James C. Hanges

\title{
Paul, Founder of Churches
}

A Study in Light of the Evidence for the Role of "Founder-Figures" in the Hellenistic-Roman Period

[Paulus als Kirchengründer. Eine Studie unter Berücksichtigung der Rolle von 'Gründerfiguren' in der hellenistisch-römischen Zeit.]

Veröffentlicht auf Englisch.

Paulus' Verständnis seiner Rolle als Gründer christlicher Kulte in neuen Territorien ist weder einzigartig noch lässt sie sich hinreichend durch jüdische Vorgänger erklären. James Constantine Hanges zeigt, wie sich Paulus das griechische Modell des Gründers, der menschlichen Schlüsselfigur in griechischen Gründungserzählungen, auf kreative Weise zu eigen macht. Epigraphische und literarische Beschreibungen zeigen, daß Gründungen nach einem bestimmten Muster unternommen wurden, das üblich für griechische Gründungserzählungen war - die orakelhafte Auswahl des Gründers und sein ultimativer Gehorsam wurden im Erfolg seiner Kulterneuerung verkörpert. Eine postkoloniale Lesart zeigt, daß Paulus die Rolle des griechischen Gründers annahm, um sie für seine Selbstdefinition zu nutzen. Er verwendet zwar wenige technische Gründungstermini, aber sein Vertrauen in die göttliche Wahl als Bestätigung für seine Vermittlung der Lehre Jesu, die Art, wie er Autorität über seine Kirchen ausübt und seine Integration der Griechen in die heilige Geschichte Israels bestätigen den Gebrauch des griechischen Modells.

James C. Hanges Born 1954; 1999 PhD, University of Chicago; since 2005 Associate Professor of Comparative Religion, Miam University, Ohio.

2012. XXIII, 550 Seiten. WUNT I 292

ISBN 978-3-16-152473-8

DOI 10.1628/978-3-16-152473-8

eBook PDF 159,00€

ISBN 978-3-16-150716-8

Leinen 159,00

Jetzt bestellen:

https://mohrsiebeck.com/buch/paul-founder-of-churches-9783161524738?no_cache=1

order@mohrsiebeck.com

Telefon: +49 (0)7071-923-17

Telefax: +49 (0)7071-51104 